\title{
EL TIEMPO DURANTE LA BATALLA DE TRAFALGAR (OCTUBRE 1805)
}

\author{
Dennis Wheeler*
}

\section{RESUMEN}

El presente trabajo analiza el tiempo atmosférico presente durante uno de los grandes eventos de la historia — la Batalla de Trafalgar-. No sólo se explica el papel fundamental que desempeñó el tiempo atmosférico en el transcurso de la batalla sino que asimismo la consulta documental ha permitido recrear las condiciones sinopticas con objeto de compararlas con las condiciones climáticas actuales en dicha área. El estudio permite valorar la utilidad de los documentos históricos en las reconstrucciones climáticas.

Palabras clave: Climatología histórica; fuentes documentales; gotas frías.

\begin{abstract}
This paper focusses on the weather at the time of one of histories great events - the Battle of Trafalgar. Not only did weather have a vital role to play in the unfolding of events at that time but the documents which have survived enable us to recreate the synoptic conditions and to compare them with presentday climate in the same area. In doing so it provides a valuable means by which we can establish the utility of historical documents for climatic reconstructions.
\end{abstract}

Key words: Historical climatology, documentary sources, «cutt-off lows».

* El autor quiere expresar su agradecimiento al profesor Javier Martín Vide (Departamento de Geografía Física y Análisis Geográfico Regional, Universidad de Barcelona) por su ayuda y su consejo en la preparación de este artículo. 


\section{Introducción}

El autor del presente artículo ya ha realizado algunos intentos de reconstrucción del tiempo meteorológico durante la batalla de Trafalgar (WHEELER, 1985), cuando la Marina Real inglesa se enfrentó a las armadas francesa y española. En aquel mes de octubre de 1805 la armada inglesa bloqueó el puerto de Cádiz, tuvo lugar la batalla y, la semana después del conflicto, una furiosa tempestad afectó al golfo de Cádiz. De particular interés, tanto para los historiadores como para los meteorólogos, resulta el estudio de la tempestad, de inusual violencia, y sus consecuencias sobre las flotas y los supervivientes de la batalla, maltrechos tras la contienda, cuya resistencia es un buen testimonio de la calidad de la marinería de aquella época.

En el presente trabajo se intenta establecer comparaciones entre las condiciones meteorológicas de aquella tempestuosa semana y otros casos más recientes similares sinópticamente, con el objeto de caracterizar la naturaleza del temporal de octubre de 1805. Esta tarea tiene evidentes limitaciones por causa de la insuficiencia de datos disponibles, a pesar de lo cual merece un cierto grado de confianza.

\section{Fuentes de datos}

Para los episodios recientes similares al de octubre de 1805 pueden encontrarse datos en las tablas diarias publicadas por el Meteorological Office del Reino Unido o por el Deutscher Wetterdienst de Alemania. En cambio, la información relativa a octubre de 1805 es inevitablemente menos precisa, geográficamente laxa y sujeta a interpretaciones erróneas y subjetivas. Al margen de estas prevenciones, existe un fondo de información sorprendente sobre el tiempo meteorológico en Europa occidental durante octubre de 1805. Un cierto número de lugares de Inglaterra tienen información fidedigna. En el observatorio de Goodwood House, en el sur de Inglaterra, se registraba la dirección del viento, la presión atmosférica y la temperatura tres veces al día. En la ciudad de Newcastle-upon-Tyne, en el noreste de Inglaterra, James Losh también registraba tres veces al día la temperatura y la presión atmosférica, al igual que Samuel Robertson en el sur de Escocia, en el pueblo de Ednam. Más al norte, en los diarios de James Ramsey, que vivió cerca de la ciudad de Perth, hay un registro diario de viento y otros elementos meteorológicos para unos cuantos años alrededor de 1805. La información sobre el continente en aquella época es más difícil de encontrar. La Revolución había dispersado las fuentes potencialmente útiles de la Societé Royal de Médecine de Francia (KINGTON, 1970), como tampoco se dispone de una gran cantidad de datos y observaciones de la Península Ibérica.

Las fuentes más valiosas han sido los diarios de navegación de los barcos que intervinieron en la batalla de Trafalgar o bloquearon los puertos atlánticos france- 


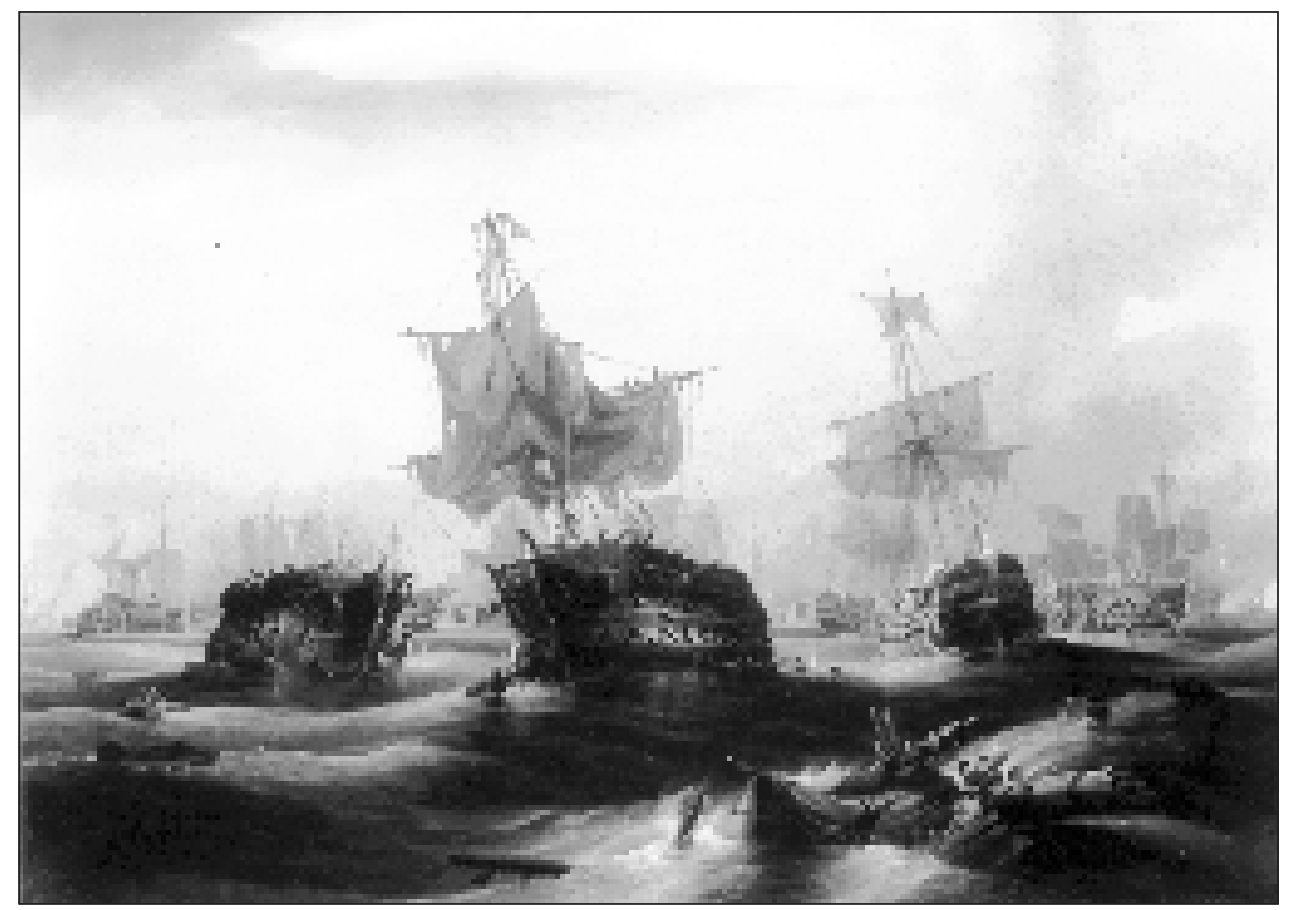

Figura 1: «Evening at Trafalgar» de William Huggins (1781-1845). Aunque el pintor no estuvo presente en la batalla, este cuadro representa el escenario después de la misma. El oleaje y los barcos batidos por la tempestad crean una precisa impresión del tiempo atmosférico (reproducido con el correspondiente permiso del National Maritime Museum, Greenwich, London).

ses. OLIVER y KINGTON (1970) han examinado la utilidad como documentos meteorológicos de tales fuentes originales, confirmando su importancia. Además de observaciones generales sobre la administración y el manejo de los navíos, los diarios prestan una detenida atención al tiempo existente durante los tres partes, o guardias, del día naval. La información meteorológica principal consiste en estimaciones de la velocidad del viento similares a las descripciones utilizadas en la escala Beaufort. Así, por ejemplo, términos tales como brisas fuertes (en inglés, strong breezes) o frescas (fresh breezes) son empleados frecuentemente, pudiendo ser asimilados sin problema a los grados 5 y 6 , respectivamente, de la escala Beaufort. La dirección del viento se registraba utilizando una rosa de los vientos de 32 rumbos. Aparece también información útil, en forma de comentarios escritos, sobre la aparición de truenos, relámpagos, chubascos, lluvia, nieblas, etc. A pesar de su carácter cualitativo, estos comentarios son muy útiles para tener una imagen de las condiciones meteorológicas del momento. Tales observaciones descriptivas se realizaban según el criterio de los capitanes, quienes se esmeraron en ellas en mayor o menor grado, por lo que varía su calidad y utilidad de un diario a 
otro, pudiendo darse algunas discrepancias entre ellos. Lamentablemente no existe ninguna información barométrica a bordo para este episodio. Por otra parte, un suceso como el bloqueo de Cádiz y la batalla de Trafalgar sirvió para reunir muchos navíos en el mismo lugar, lo que permite a los investigadores revisar la concordancia de sus anotaciones. En el caso de estudio no existen diferencias importantes entre los doce diarios ingleses elegidos para el análisis. Además, WHEELER (1988) ha demostrado que los tipos de observaciones de la fuerza y la dirección del viento que se hacen a bordo de barcos de vela son válidas. A pesar de la concentración de barcos, la extensión geográfica cubierta por tal información es pequeña, con huecos entre las principales áreas de actividad naval. Además, las observaciones se limitan inevitablemente a aquellos aspectos más importantes para los marineros, como son la fuerza y la dirección del viento, mientras que las cantidades de precipitación y las temperaturas están ausentes de las notas escritas por los capitanes.

Una información suplementaria puede sacarse de las cartas y los informes privados que los marineros y los almirantes franco-españoles e ingleses escribieron después de la batalla. Estos documentos carecen del detalle meteorológico que es típico en los diarios de los capitanes, pero con frecuencia contienen descripciones de condiciones vividas.

Los estragos de la tempestad después de la batalla de Trafalgar dañaron de igual modo a los contendientes, lo que queda reflejado de forma muy notable en la correspondencia privada y en los documentos oficiales de la época. No puede ponerse en duda la severidad de la tempestad y sus vientos. Los diarios de navegación registran temporal duro (equivalente a fuerza 9 en la escala Beaufort) casi continuo, con un máximo el día 26. Frederick Ruckert, maestre del Euryalus, la fragata más importante de la flota inglesa, anotó en la mañana del día 23: «... «galernas» y lluvia fuerte con vientos duros. El estay del mástil se parte y es destruido por una fuerte ráfaga del oeste...». El cúter inglés Entrepenante fue incluso menos afortunado. Su diario registra: «...galernas» duras con mar muy agitada. Se parte la vela mayor...entró mucha agua». El Entrepenante sobrevivió, sin embargo, y alcanzó el abrigo de Gibraltar el 26 de octubre. Thomas Watson, el maestre del navío inglés Achille, escribió en su diario el 23 de octubre: «...galernas» fuertes con chaparrones, a las 9 la guindaleza del barco español apresado que remolcábamos se quebró. A las 11 «galernas» fuertes y vientos intensos con lluvia. Se parte el estay mayor». Los diarios de cada navío que sobrevivió a la tempestad relatan la misma historia, variando únicamente en las estimaciones de los momentos exactos de los acontecimientos, la fuerza de los vientos y la severidad del tiempo.

Las cartas de los marineros no son menos elocuentes ni informativas con respecto al tiempo. El veterano capitán de la fragata Euryalus, Henry Blackwood, escribió a su esposa el 23 de octubre: «...había soplado como si fuera un huracán». 
Más tarde, el día 22 de noviembre, Henry Walker, un guardiamarina del navío Bellerophon, escribió una carta a su madre que contiene esta descripción del tiempo en las horas posteriores a la batalla: «...pero durante la noche (del 21 de octubre) llegó una tempestad que nunca había visto antes, y durante los cuatro días siguientes luchamos contra los elementos, mucho más duros que el enemigo». El tiempo del día de la batalla había sido, sin embargo, tranquilo, como también lo había sido el del período de bloqueo de las tres semanas anteriores. Durante aquellas semanas habían dominado unas condiciones anticiclónicas, lo que favoreció a la flota inglesa y a la comunicación entre sus navíos (WHEELER, 1985). Fueron comunes vientos ligeros y calmas. Bajo tales condiciones el 20 de octubre la flota franco-española salió del abrigo de Cádiz hacia el sur y el estrecho de Gibraltar. Durante la noche siguiente le persiguió la flota inglesa. Al amanecer del 21 de octubre tan sólo 15 kilómetros separaban a las dos armadas, pero no entraron en batalla hasta las tres de la tarde. La flota inglesa se dispuso en dos columnas alineadas vagamente. Continuó la persecución, pero el viento sopló flojo y, aunque los navíos ingleses desplegaron tantas velas como fue posible, avanzaron sólo poco más de dos nudos hacia la flota franco-española, que navegaba en línea cerca de la costa gaditana. Los sucesos de aquel día horrible dieron paso a un oleaje creciente del oeste, que obligó al propio almirante Nelson de la flota inglesa a dedicarle todos sus esfuerzos después de la batalla y hasta en su agonía, consciente de lo amenazante de la tempestad anunciada por el estado del mar, instando al capitán de su navío Victory, capitán Hardy, a que anclara la flota para evitar daños en las tripulaciones si se dirigían hacia la cota rocosa del cabo Trafalgar.

El amenazador oleaje del oeste que anunció la tempestad fue también anotado tan pronto como la noche del 20 de octubre por el capitán Jean Jacques Lucas del barco francés Redoutable. La mayoría de los diarios de los barcos ingleses hacen su primera anotación sobre el oleaje un poco más tarde. Estas discrepancias en el tiempo cronológico no son raras, haciendo difícil establecer la hora de llegada de la tempestad a las flotas, aunque lo más probable es que se produjera cerca del mediodía del 22 de octubre. La tempestad persistió, con algunas fluctuaciones en su intensidad, hasta el 29 de octubre. Durante todo ese tiempo los vientos observados fueron principalmente entre oeste y sur-suroeste. De todos modos, no hay que esperar una concordancia perfecta entre todos los diarios, y, así, el del barco inglés Royal Sovereign anota, por ejemplo, vientos del noroeste. Afortunadamente disponemos de un buen número de diarios y por ello es posible determinar la dirección más probable del viento. Además, la información de ciertos barcos en navegación por otros sectores del Atlántico oriental contribuyen a tener una información más amplia de la circulación del viento.

Más al norte, una flota inglesa más pequeña que bloqueaba el puerto francés de Brest tuvo que enfrentarse a vientos fuertes del este o del sureste, mientras la tempestad del suroeste afectaba al golfo de Cádiz. Este es un dato de gran impor- 
tancia, porque parece revelar que la perturbación, o el sistema de presión responsable de aquellos efectos, tenía una gran extensión, alcanzando esas latitudes septentrionales. Este hecho nos permite sugerir que el centro de la perturbación se situaba aproximadamente a mitad de camino entre el golfo de Cádiz y la costa de Bretaña, quizás a una latitud de $43^{\circ} \mathrm{N}$ al oeste del cabo Finisterre. La fuerza y la persistencia de la tempestad indican que la presión en el núcleo de la perturbación debía de ser muy baja. Ciertos documentos en los archivos del observatorio de San Fernando (WHEELER, 1992), uno de los más antiguos de España, indican que en aquel tiempo habían sido enviados a capitanes de barcos españoles barómetros marítimos, al igual que los capitanes ingleses también los utilizaban. Desafortunadamente, hoy no nos ha llegado ningún registro de las observaciones realizadas con aquellos barómetros. Tampoco se conoce la existencia de registros tomados en las áreas costeras francesa y española. El observatorio de San Fernando tiene observaciones de presión atmosférica para la mayoría de los días de la década de 1790 a 1800, pero tiene muy pocos registros de la década siguiente, excepto de temperaturas medias y totales de precipitación mensuales. Los registros de presión atmosférica de los observadores ingleses y escoceses resultan demasiado alejados del centro de la perturbación como para aportar luz, aunque revelan valores altos sobre las islas Británicas. Todo ello indica la presencia de un anticiclón de bloqueo y un flujo con índice zonal muy bajo en altitud. Por consiguiente, las bajas atlánticas debían seguir trayectorias desviadas al norte o al sur de lo normal.

\section{Interpretación e hipótesis}

Ciertas características de la tempestad de Gibraltar pueden establecerse a partir de las informaciones que disponemos: su carácter ciclónico, su duración y su aparente inmovilidad y, más marcadamente, su gran intensidad y extensión geográfica. Con base en estas conclusiones y en las observaciones de los diarios de navegación y en otras, se va a intentar realizar una interpretación de la situación atmosférica durante aquel suceso lejano en el tiempo.

Podríamos estar persuadidos, en base a la experiencia vivida por el capitán Blackwood, a interpretar la tempestad como un verdadero huracán, pero hay buenas razones para no hacerlo así. En primer lugar, el uso por parte de Blackwood del término huracán es ambiguo, porque, aunque al menos un diccionario de la época (FALCONER, 1771) reconoce su naturaleza tropical, su verdadera definición no era entonces entendida, utilizando el término la mayoría de los capitanes para designar cualquier tormenta fuerte y violenta. Además podemos rechazar la hipótesis del huracán por razones más científicas. En un estudio de NEWMANN et al. (1981) sobre las trayectorias de los huracanes en el Atlántico norte entre 1871 y 1980 no se encuentra ni un ejemplo de huracán que entre en el área meridional de España. La mayoría de los huracanes en su regreso del mar 
Caribe por el Atlántico norte siguen unas derrotas mucho más septentrionales. Hay una cierta tendencia de que los huracanes tardíos tomen vías ligeramente más al sur, pero no en un grado suficiente como para traerlos al golfo de Cádiz. No solamente debemos ser cautos ante el empleo de términos tales como huracán, sino también en otros como «galerna», que es aplicado confusamente, de lo cual tenemos un buen ejemplo en el diario de uno de los capitanes ingleses que luchó en Gibraltar. El capitán Henry del navío Africa (el barco más pequeño que participó en la batalla) preparó un diario en el que se refiere frecuentemente antes de la batalla a «galernas», cuando otros capitanes registran a lo sumo brisas fuertes (fuerza 6 en la escala Beaufort). Esta discrepancia muestra el uso ambiguo que en ocasiones se hace de ciertos términos. El capitán Digby es menos culpable de interpretar erróneamente la fuerza del viento que de utilizar una definición muy vieja que equiparaba vientos tan flojos como una brisa con «galernas». Hacia 1805 este uso del término cayó en un desuso casi completo².

A pesar del rechazo de la hipótesis del huracán, hay evidencias de la existencia de al menos una tormenta tropical en el Atlántico en aquel mes. Un clérigo que vivía en Nueva Inglaterra, James Bentley, describe una tormenta que se abatió sobre la costa de Maine el 3 de octubre de 1805: «...por la mañana comenzó a llover por el noreste, aumentó el viento hasta el mediodía, soplando entonces violentamente. Las casas, graneros, árboles y cercas fueron devastados...por lo que fue denominado tornado, huracán y tormenta». La terminología ambigua empleada por Bentley nos avisa de las dificultades y de la necesidad de un sentido crítico con respecto a las fuentes escritas de aquella época. Parece, sin embargo, que fue una tempestad severa de algún tipo, pero no la misma con la que se encontraron los restos de las armadas franco-española e inglesa a la altura del cabo Trafalgar diecinueve días más tarde en aquel mes. De hecho, la mayor aproximación de un huracán a las costas ibéricas desde el siglo pasado fue la del Louis, en noviembre de 1966, que, aunque en su fase final, alcanzó un punto a $700 \mathrm{~km}$ al oeste del cabo Finisterre, donde se rellenó finalmente el día 14 . Generalizando, «...muy pocas depresiones entran en la región (las aguas del Atlántico oriental entre las Azores e Inglaterra) en forma de huracanes bien desarrollados» (METEOROLOGICAL OFFICE, 1978).

Las tormentas y los temporales han sido durante siglos un bien conocido riesgo en el golfo de Cádiz. Los archivos de Lloyds of London contienen un interesante memorando anónimo de principios del siglo pasado sobre una tormenta a la altura del cabo Trafalgar, que comienza así: «La gente ignorante de la navegación costera entre el cabo Trafalgar y el cabo St. Maries (sic) está muy alarmada ante un temporal del suroeste y quiere tener conocimientos adecuados sobre cómo se

2 El término «galerna» usado en el texto no tiene que ver, por otra parte, con las características galernas del Cantábrico, sino con un viento o temporal duro, sin precisión de su componente. 
desarrollan y les causan frecuentemente dificultades. El temporal sopla del sur en su inicio durante seis u ocho horas, pero al mismo tiempo el mar es del oeste». El informe continúa describiendo cómo el viento vira al suroeste cuando la tormenta se aproxima.

Son tan característicos estos temporales del suroeste que reciben la denominación local de vendavales. Pero, lo que es más importante, su secuencia general tiene una semejanza casi completa con los sucesos meteorológicos producidos durante y después de la batalla de Trafalgar. Así, al zarpar de Cádiz hacia el estrecho de Gibraltar los almirantes franceses y españoles se quejan de su lento progreso hacia el sur debido a los vientos contrarios. El oleaje del oeste y la llegada más tarde del temporal del suroeste ya se han descrito.

El golfo de Cádiz tiene una situación demasiado meridional como para experimentar frecuentes visitas de las bajas o depresiones tan corrientes en el norte de Europa. Sin embargo, el golfo se halla en una zona donde son comunes el tipo de sistema conocido por el nombre de «cut-off low». Normalmente estos sistemas están acompañados por embolsamientos fríos en altitud («gota fría»). Esta es la explicación más probable de la tempestad de la batalla de Trafalgar.

Es posible, además, realizar comparaciones útiles con acontecimientos meteorológicos más recientes de este tipo de los cuales poseemos mapas, datos y un conocimiento más profundo. La METEOROLOGICAL OFFICE (1978) ha demostrado ya que octubre y noviembre son los meses en que las bajas son más frecuentes. En un estudio sobre diez años, fueron detectadas 75 de las cuales 20 se produjeron durante esos dos meses. Muchas persistieron sólo unos días, pero, significativamente, casi el 20 por ciento duraron una semana o más tiempo. CAPEL MOLINA (1980) ha mostrado que el desarrollo de corrientes meridionales en altitud conduce al desarrollo de gotas frías en las latitudes ibéricas entre 35 y $45^{\circ}$ N. Sobre las trayectorias seguidas por las bajas, el 36 por ciento se trasladó al este hacia el golfo de Cádiz y tantas como la mitad de ellas se rellenaron a la altura de la costa peninsular y no atravesaron el estrecho de Gibraltar. En esa posición casi estacionaria estas bajas aportan a las provincias de Cádiz y Huelva algunas de las precipitaciones más importantes y los vientos más fuertes.

Las características generales de la tempestad de Trafalgar, la fecha del suceso, su ubicación y su comportamiento se ajustan muy estrechamente a las de un proceso de «cut-off low». Tal interpretación se refuerza cuando examinamos con detalle las condiciones sobre las islas Británicas en aquel momento. Las observaciones barométricas que se hicieron en el sur de Inglaterra (Goodwood House), en el noreste de Inglaterra (por James Losh en Newcastle upon Tyne) y en el sur de Escocia (Ednam) indican un aumento de la presión el 18 de octubre. Las condiciones anticiclónicas duraron hasta el 24 de octubre. Aunque la corrección de estas observaciones al nivel del mar es difícil, se ve, no obstante, un claro aumento de la presión en dirección al norte. En Newcastle hubo 1030 hPa, aproximadamente 5 


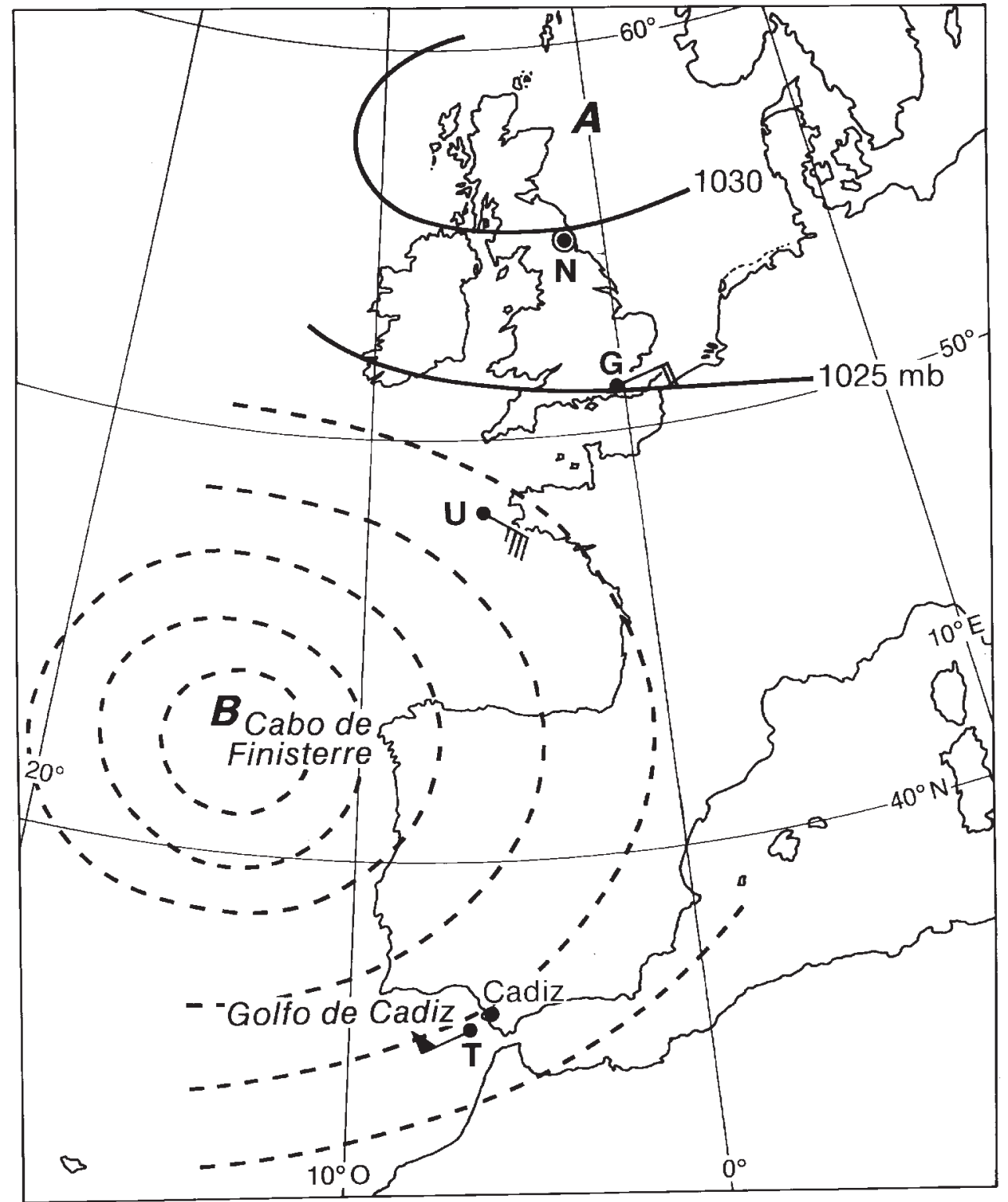

Figura 2: Mapa de superficie reconstruido del 22 de octubre de 1805. Los símbolos convencionales indican la fuerza del viento en Trafalgar (T), Ushant (U), Goodwood House (G) y Newcastle upon Tyne $(\mathrm{N})$. Las isobaras en Inglaterra son precisas, pero las restantes no se pueden asegurar con total confianza.

hPa más que en Goodwood House (400 km al sur). Además, Newcastle registró heladas el 20 y el 21 de octubre y en Ednam se produjeron el 19, 20 y 21. El tiempo en ambos lugares se describe como claro, despejado, seco y en calma. Más 
al norte, en la ciudad de Perth, James Ramsey registró calmas en su diario meteorológico desde el 19 hasta el 22 de octubre, con heladas todas las noches, y habiendo caído ya nieve en la colinas cercanas. Los vientos fueron flojos y variables en Inglaterra y Escocia durante ese período. Las evidencias acumuladas de estos registros apuntan claramente a unas condiciones anticiclónicas en las latitudes septentrionales. Es la consecuencia lógica de que existiera en aquel período un índice zonal muy bajo en los vientos del oeste de altitud. Tales condiciones favorecen el desarrollo de una gota fría en latitudes más meridionales (BOYDEN, 1963).

El sur de Inglaterra quedó en una situación periférica tanto para la tempestad como, en menor grado, para el anticiclón dominante sobre el norte de Inglaterra. En Goodwood House los registros indican brisas fuertes del este o del noreste y temperaturas $9^{\circ} \mathrm{F}$ (aproximadamente $4^{\circ} \mathrm{C}$ ) más altas que las de Newcastle upon Tyne. El diario del barco inglés Foudroyant hace referencia a «galernas» del sureste el 22, 23 y 24 de octubre, días en los cuales sufrió estas condiciones desfavorables a unos $70 \mathrm{~km}$ de la isla de Ushant, cuando la escuadra inglesa estaba bloqueando el puerto francés de Brest. La figura 2 refleja la distribución general de la presión atmosférica el 22 de octubre de 1805, basada en los registros citados en los párrafos anteriores.

La fecha más probable de comienzo de la tempestad es el 19 de octubre en un lugar al oeste del cabo Finisterre, aproximadamente a $15^{\circ}$ de longitud. La llegada de un flujo de aire en altura sobre el Atlántico oriental en aquella estación del año encontró el océano en su estado más cálido, con unas temperaturas superficiales de entre 17 y $20^{\circ} \mathrm{C}$, lo que daría lugar a una fuerte inestabilización de la atmósfera y a una actividad ciclónica intensa. Tales irrupciones hacia el sur de aire frío en esa época del año son características del clima español y frecuentemente ocasionan una finalización muy brusca de la estación estival. Sobre esto, la cita siguiente, que concierne al paso del verano al otoño, marcado por una disminución acusada de la presión en el Mediterráneo occidental, es particularmente pertinente: «por lo que se refiere a los ritmos de presión, la característica más destacada es el comienzo del otoño, que aparece claramente hacia el 20 de octubre en las curvas de presión media en todas partes, desde Perpignan y Gibraltar a Malta...» (METEOROLOGICAL OFFICE, 1962). Sin embargo, la duración del anticiclón del norte no concuerda con la de la tempestad. El primero desapareció el 24 de octubre, siendo reemplazado sobre Inglaterra por unas condiciones más moderadas y húmedas. Los vientos soplaron moderados y frescos del noreste hasta el día 28 en todas las islas Británicas. El tiempo fue ocasionalmente soleado, pero con chubascos en el norte y lluvia más persistente y frecuente en el sur. Los datos de las observaciones del pastor James Cowe de Sunbury (al oeste de Londres) dan 21,8 mm de lluvia el 24 de octubre, nada el $25,12,2 \mathrm{~mm}$ el 26 y $2,5 \mathrm{~mm}$ el 27 . Tal imagen de vientos lluviosos del noreste sugiere el paso hacia el este de una baja al sur de la región. El diario del navío inglés Foudroyant indica que los vientos fuertes de los días 


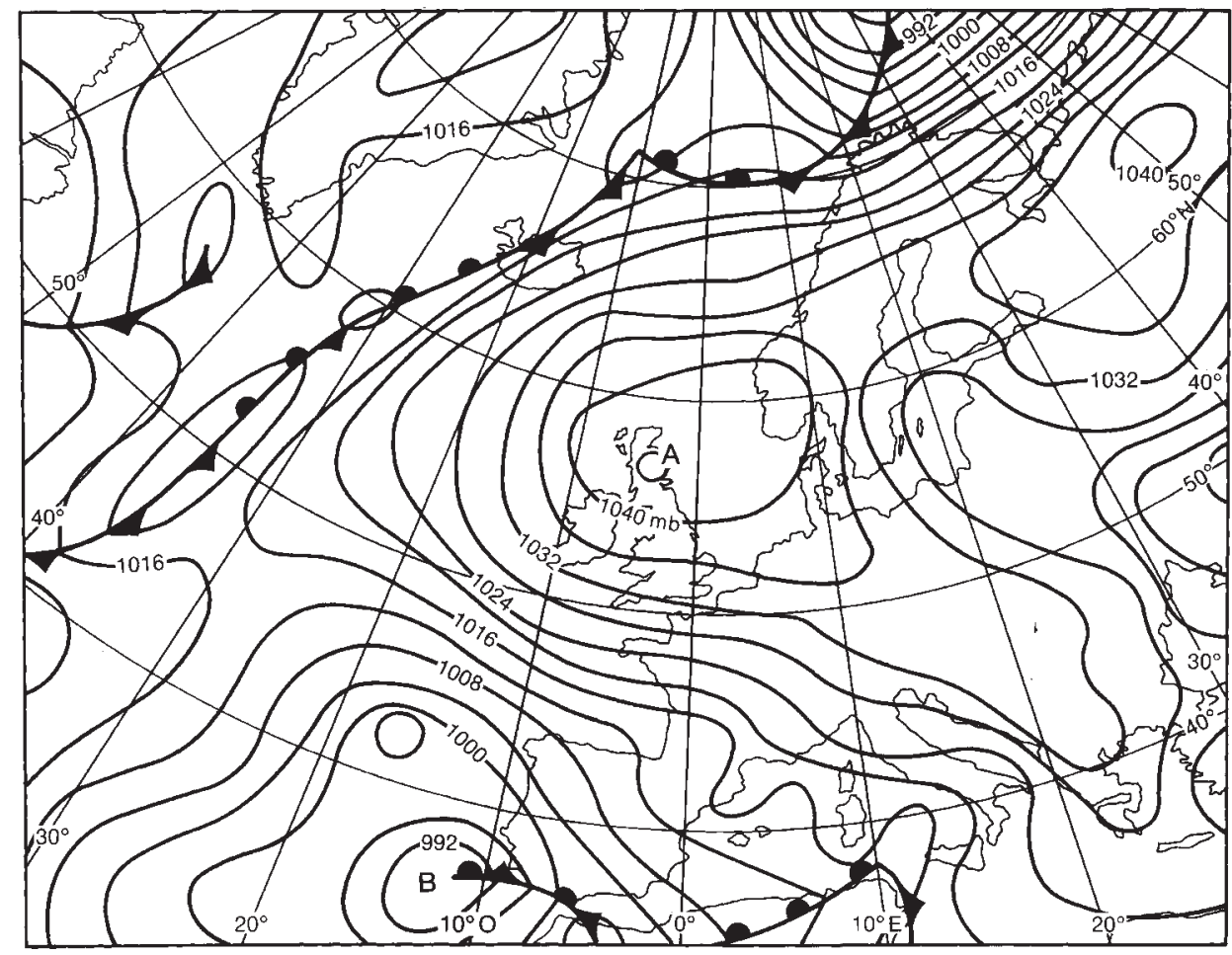

Figura 3: Mapa de superficie, a las 12.00 TMG, del 17 de enero de 1963. La situación general se parece a la del 21 de octubre de 1805 . El viento en el golfo de Cádiz es algo menos fuerte, pero en otros aspectos la configuración bárica es parecida.

anteriores fueron sustituidos por tiempo lluvioso con vientos variables el 25 de octubre. Es posible, por tanto, que el centro de la baja pasara a través del Canal de la Mancha, por donde ese barco navegaba. Sin embargo, esta depresión debía de ser pequeña, no tan grande como la tempestad del sur.

Mientras tanto, la tempestad continuaba en el golfo de Cádiz, pudiendo la desaparición del anticiclón reforzarla. Hay indicios en la documentación que el 25 de octubre la tempestad mostró signos de debilitamiento, señalando los diarios que las «galernas» fueron sustituidas por brisas fuertes. Este debilitamiento cesó el 26 de octubre, cuando los vientos se transformaron en los más violentos de la semana. Las condiciones fueron tan malas que el almirante inglés a cargo de la flota después de la muerte de Nelson, Cuthbert Collingwood, ordenó que los bienes capturados durante la batalla fueran abandonados. Esta era una medida extrema, dado el gran valor económico que tenían tales capturas para los marineros, sólo explicable por el cambio tan marcado en el estado del tiempo. El empeoramiento pudo haber sido la consecuencia de la llegada de aire frío del norte que siguió al paso de la baja descrita en el párrafo precedente. La oleada de aire frío en los 
niveles altos alimentó de nuevo a la depresión, que persistió entonces hasta su desaparición el 29 de octubre.

\section{Casos análogos}

Los comportamientos de las depresiones frías son suficientemente característicos como para haber permitido a BOYDEN (1963) identificar algunos criterios útiles para su predicción y clasificación. La configuración que se resume en la figura 2 también constituye uno de los tipos de tiempo clasificados en los esquemas propuestos por CAPEL MOLINA (1981) y FONT TULLOT (1983). No obstante, una búsqueda sobre los últimos 25 años de mapas meteorológicos ha resultado infructuosa en la consecución de una secuencia tan persistente que concuerde con la de aquella semana decisiva de octubre de 1805. Dada la variabilidad inherente al sistema climático, esto no resulta raro y no sirve para refutar los argumentos ofrecidos anteriormente. Es importante notar también que COLMAN (1986) ha mostrado que las primeras dos décadas del siglo XIX fueron de las más frías de los últimos dos siglos en el hemisferio norte. También FONT TULLOT (1983) ha señalado que el clima de principios del siglo XIX fue bastante variable, más que hoy día, y que los efectos de la Pequeña Edad de Hielo eran todavía importantes. Por causa de estas diferencias en las condiciones climáticas generales la comparación no puede ser perfecta. Se han encontrado, no obstante, algunas situaciones en que se repitieron, al menos en parte, las condiciones de octubre de 1805 en un sentido general, aunque no en tal grado y persistencia.

No es difícil encontrar algunos casos análogos bastante semejantes a la primera fase de la tempestad, entre el 20 y el 24 de octubre. FONT TULLOT (1983) clasificaría la figura 2 en su tipo de tiempo número 12.1.D (depresión atlánticoibérica), utilizando como ejemplo el caso del 25 de noviembre de 1977. El autor del presente trabajo ha descubierto un caso más parecido, que tuvo lugar hacia finales de enero de 1963. La situación en la última parte de este mes es de particular interés. Un anticiclón se centró sobre las islas Británicas y dio lugar a un tiempo frío con $5,3^{\circ} \mathrm{C}$ por debajo del promedio, siendo en algunos lugares el mes más frío desde enero de 1838. Estas condiciones meteorológicas recuerdan las de octubre de 1805. Por ejemplo, BIRKLAND (1949) ha mostrado que en Noruega en octubre de 1805 hubo unas temperaturas de casi tres grados centígrados por debajo de la media y que sólo ha habido seis octubres más fríos en el período comprendido entre 1762 y 1946. En Inglaterra, MANLEY (1974) también decsubrió que el octubre de 1805 fue frío, con casi dos grados por debajo de la media. Desde 1926 no se ha dado en su conocida serie de temperaturas de Inglaterra central un octubre más frío.

Podemos comparar los sucesos meteorológicos del 17 al 29 de enero de 1963 con las condiciones descritas en los párrafos precedentes. En realidad, en ese 


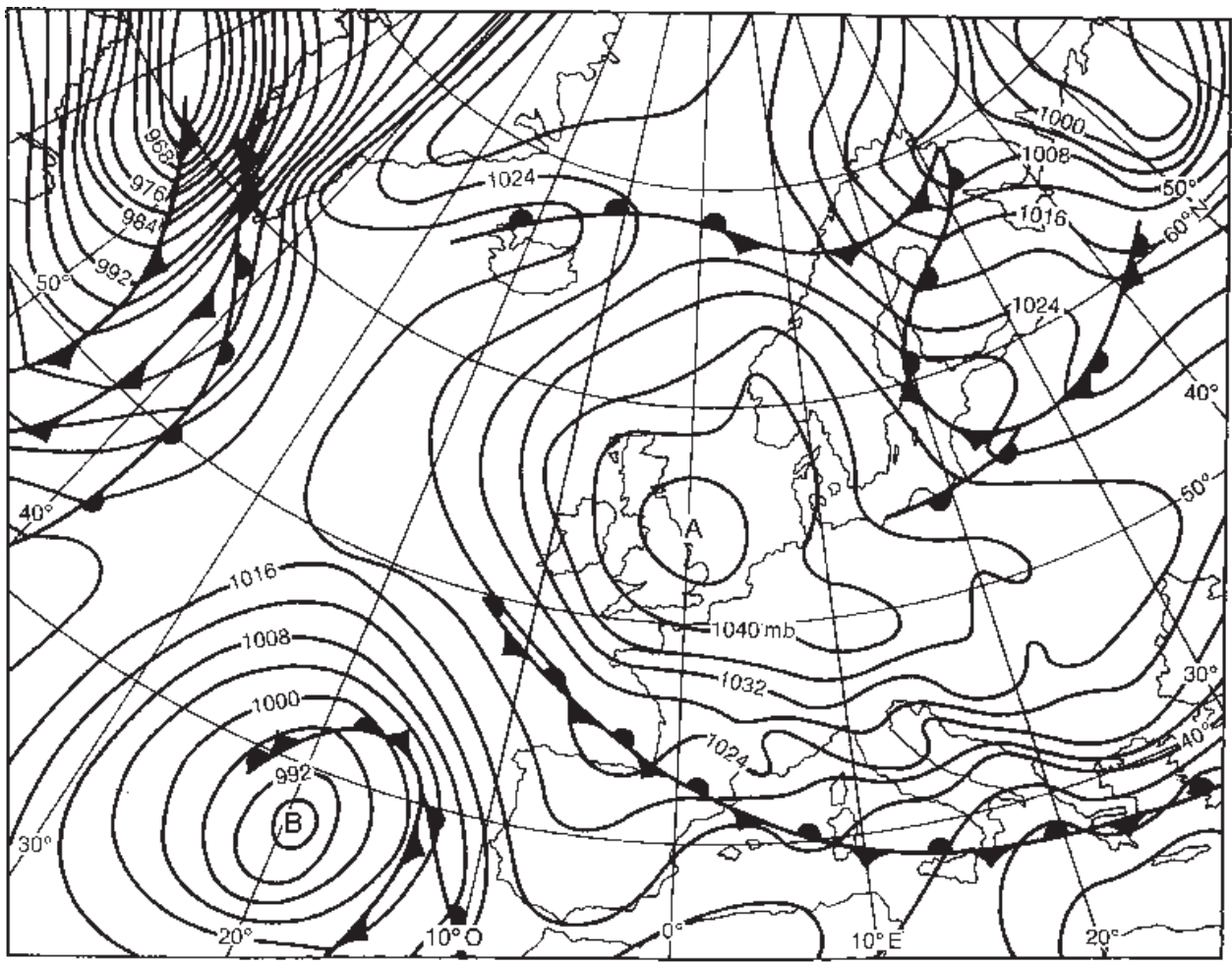

Figura 4: Mapa de superficie, a las 12.00 TMG, del 22 de enero de 1963. Se acerca a la Península Ibérica una depresión bien desarrollada, mientras un anticiclón se sitúa sobre Inglaterrra. Los dos centros indican un índice de circulación de los vientos del oeste bajo, con un embolsamiento frío sobre la depresión. Esta configuración bárica probablemente se parece a la del 20 de octubre de 1805, el día anterior a la batalla, cuando la tempestad aún no había llegado.

período de dos semanas se desarrollaron dos situaciones frente a la Península Ibérica que tuvieron similitudes con la primera fase del tiempo del episodio de la batalla de Trafalgar. El 17 de enero (figura 3) el bien establecido anticiclón sobre Inglaterra y la depresión con centro al oeste del golfo de Cádiz configuran una situación parecida a la de octubre de 1805. El anticiclón y la baja de 1963 tuvieron menos desarrollo, pero sus ubicaciones y sus circulaciones generales se corresponden estrechamente con las del 22 de octubre de 1805, indicando vientos del suroeste en el golfo de Cádiz y vientos del este y sureste en el Canal de la Mancha $\mathrm{y}$, finalmente, condiciones de calma sobre el norte de Inglaterra. Sin embargo, la depresión tomó entonces un rumbo poco común hacia el norte a lo largo de la costa peninsular hasta rellenarse el 20 de enero cerca del cabo Finisterre. El sistema fue, aparentemente, de menor duración y más móvil que su predecesor de 1805. El anticiclón del norte persistió después de desaparecida la baja, manteniéndose durante el segundo episodio análogo, que comenzó el 21 de enero de 1963. 
El anticiclón del segundo episodio (figura 4) fue, en realidad, el resultado de la unión del anticiclón de Inglaterra con otro sistema sobre Groenlandia. La unión tuvo lugar el 19 de enero. Este nuevo sistema se movió lentamente hacia el sureste, situándose a la altura de la costa del noreste de Inglaterra el 22 de enero. La depresión grande y activa que se formó a $43^{\circ} \mathrm{N} 38^{\circ} \mathrm{W}$ se movió entonces en dirección sureste. La situación meteorológica que se presenta en la figura 4 es parecida a la del día de la batalla, el 21 de octubre de 1805, cuando los vientos suaves dieron paso a otros más violentos en el golfo de Cádiz mientras avanzaba la depresión. Aunque este sistema de 1963 persistió hasta el 29 de enero, siendo, así, igual su duración a la del episodio de 1805 , no siguió un rumbo este, sino que, por el contrario, se mantuvo a una distancia de muchos kilómetros al oeste de la costa española, sobre la que tuvo una influencia pequeña. El anticiclón de bloqueo también permaneció activo en el norte, donde impidió cualquier movimiento de aire frío hacia el sur tal como el que reactivó la tempestad de octubre de 1805.

\section{Conclusión}

La naturaleza de los sucesos meteorológicos impide que haya dos idénticos, pero existen características y parecidos en causas y consecuencias; en caso contrario no existiría la ciencia de la Climatología. En este trabajo se ha intentado reconstruir el tipo de tiempo de un suceso histórico muy crítico en el que el tiempo ejerció una influencia profunda. La tempestad de la batalla de Trafalgar amenazó con destruir tanto al bando inglés como a los supervivientes franco-españoles de aquella horrible contienda. Si hubiese llegado 48 horas antes, la flota francoespañola podría haberse salvado, así como la inglesa se hubiera dispersado. Al mismo tiempo, un nuevo almirante viajó de Madrid a Cádiz para tomar el mando de la flota. Si el almirante Rosily hubiera llegado antes que el almirante Villeneuve se hiciera a la mar, la situación habría sido diferente, y una de las batallas navales más importante en la historia no hubiera tenido lugar. Las dificultades por encontrar un caso análogo en fuerza y duración de la tempestad confirma la visión de los marineros de aquel tiempo, que aseguraron que fue una tormenta de una notable violencia.

Este estudio se ha basado en informaciones instrumental y cualitativa, las cuales permiten tener una visión concordante de las condiciones de aquel episodio. La coherencia avala que esas fuentes de datos constituyen unos medios de confianza para reconstruir los climas del pasado. Esto es igualmente importante en un sentido más amplio, el de los cambios climáticos, para cuyo estudio cualquier nuevo método que pueda dar un imagen más clara de las condiciones del pasado ayuda en nuestra búsqueda de un mejor conocimiento de los mecanismos que gobiernan el clima actual. 


\section{Bibliografía citada}

BIRKELAND, B.J. (1949): «Old meteorological observations at Trondheim. Geofysiske Publikasjoner, XV, Norsk Videnskaps-Academi i Oslo.

BOYDEN, C.J.(1963): «Development of the jet stream and cut-off circulations». Meteorol.Mag., 92, pp. 287-299.

CAPEL MOLINA, J.J. (1980): Los Climas de España, Barcelona, Oikos-tau.

COLMAN, A.R. (1986): «Northern Hemisphere temperature fluctuations within the instrumental period». J.Meteorology, 11, pp. 306-312.

FALCONER, W. (1771): An Universal Dictionary of the Marine, London, T. Cadell. FONT TULLOT, I. (1983): Historia del clima de España: cambios climáticos y sus causas, Madrid, Instituto Nacional de Meteorología.

KINGTON, J.A. (1970): «A late eighteenth century source of meteorological data». Weather, 25, pp. 169-175.

MANLEY, G. (1974): «Central England temperatures: monthly means 1659 to 1973». Q.J.R.Meteorol.Soc., 100, pp. 389-405.

METEOROLOGICAL OFFICE (1962): Weather in the Mediterranean, I (2ºd.), London, HMSO.

METEOROLOGICAL OFFICE (1979): Weather in Home Waters, III: the waters around the Azores and off south-west Europe and off north-west Africa. London, HMSO.

NEUMANN, C.J.; CRY, G.W.; CASO, E.L. y JARVINEN, B.R. (1981): Tropical cyclones of the north Atlantic Ocean 1871-1980, Ashville NC, NOAA.

OLIVER, J. y KINGTON, J.A. (1970): «The usefulness of ships'logs in the synoptic analysis of past climates». Weather, 25, pp. 520-528.

WHEELER, D.A. (1985): «The weather at the battle of Trafalgar». Weather, 40, pp. 338-346.

WHEELER, D.A. (1988): «The use of ships'logs in meteorological studies: a test case». J.Meteorology (UK), 13, pp. 122-125.

WHEELER, D.A. (1992): «The Royal Observatory of San Fernando (Cádiz) and its place in the development of meteorological studies in Spain». Weather, 47, pp. 56-63. 